\title{
The 1 Value Out of the Simple Fractions of 1 Alters the Present 9 Digits
}

\section{Kutty COJ*}

Department of Mathematics, Promoters of Superscience, Bhagwati Garden, Jain Road, Uttam Nagar, New Delhi, India

\begin{abstract}
If the Simple fractions of 1 such as $0 \rightarrow 1 / 4 \rightarrow 1 / 2 \rightarrow 3 / 4 \rightarrow$ till the marking of 1 give a one value, the Mixed fractions

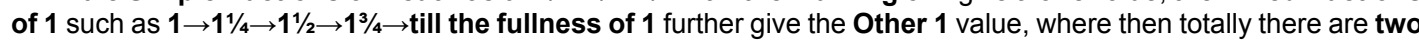
$1^{\mathrm{s}}$. From the added value of the two values of these two $1^{\mathrm{s}}$, here Digit 2 originates. Similar to the Digit Other 1, Digit 2 is having only the Mixed fractions such as $2 \rightarrow 2^{1 / 1} \rightarrow 2^{1} / 2 \rightarrow 23 / 4 \rightarrow$ till the fullness of 2 and similarly Digit 3 is having only the Mixed fractions such as $3 \rightarrow 31 / 4 \rightarrow 31 / 2 \rightarrow 3 \frac{3}{4} \rightarrow$ till the fullness of 3 , and so on with the same stage of the Mixed fractions till Digit 9 . This is because there are no Simple fractions for 2 or 3 or for any further digits till Digit 9.
\end{abstract}

Keywords: Fractions; Digit

\section{Introduction}

So there are 9 Mixed fractions as 9 normal digits.

1. Mixed fractions of 1 start from the marking of 1 as Digit Other 1

2. Mixed fractions of 2 start from the marking of 2 as Digit 2

3. Mixed fractions of 3 start from the marking of 3 as Digit 3

4. Mixed fractions of 4 start from the marking of 4 as Digit 4

5. Mixed fractions of 5 start from the marking of 5 as Digit 5

6. Mixed fractions of 6 start from the marking of 6 as Digit 6

7. Mixed fractions of 7 start from the marking of 7 as Digit 7

8. Mixed fractions of 8 start from the marking of 8 as Digit 8

9. Mixed fractions of 9 start from the marking of 9 as Digit $9[1,2]$.

But the simple fractions of 1 starting from 0 give the real 1 value

In addition to the above-seen 9 Mixed fractions as 9 normal digits, at the very left side of all of them, that is at the beginning, there are the Simple fractions of 1 as the Digit Real 1, which is with all the Simple fractions of 1 that end in $\mathbf{0 1}$, with its meaning conveyed as the $\mathbf{1}$ value starting from the marking of 0 till the 01 that touches the marking of 1 at its left side. So there are 10 Digits starting from the Digit Real $1[3,4]$. The 01 makes the way for the Digit Real 1 , which contains only the Simple fractions of 1 that start from 0 . The $\mathbf{0 1}$, further when a little more developed into the Real 1 value till the marking of 1 or till the beginning of 1 , is the Digit 1. Nevertheless, from the marking of 1 to its right side start the Mixed fractions of 1 (Figure 1).

In the Simple fractions of 1, ' 0 ' seen at the very left side is the starting point

So, this Beginning value 0 at the very left side is valuable in the Simple fractions of 1 .

Both the Simple fractions of 1 and its Beginning value 0 are not applicable in the Counting value. Rather, the counting starts from the Other 1, only from which start the Mixed fractions of 1 . But for the Space value and for the Circle value, both the Simple fractions of 1 and its Beginning value 0 are applicable valuably $[5,6]$.

So, on all the scales used to measure the Space value, ' 0 ' is marked as the Beginning value in Figure 2.
Apart from 1 in use for counting (as the 1 with the mixed fractions of 1 in that 1), there is a one value still at the left side, that is from 0 till the marking of 1 or till the beginning of 1 , where there are all the Simple fractions of 1 with the Real 1 value out of all those Simple fractions. This shows that the Simple fractions of 1 from 0 till the beginning of 1 give the Real 1 value [7-10].
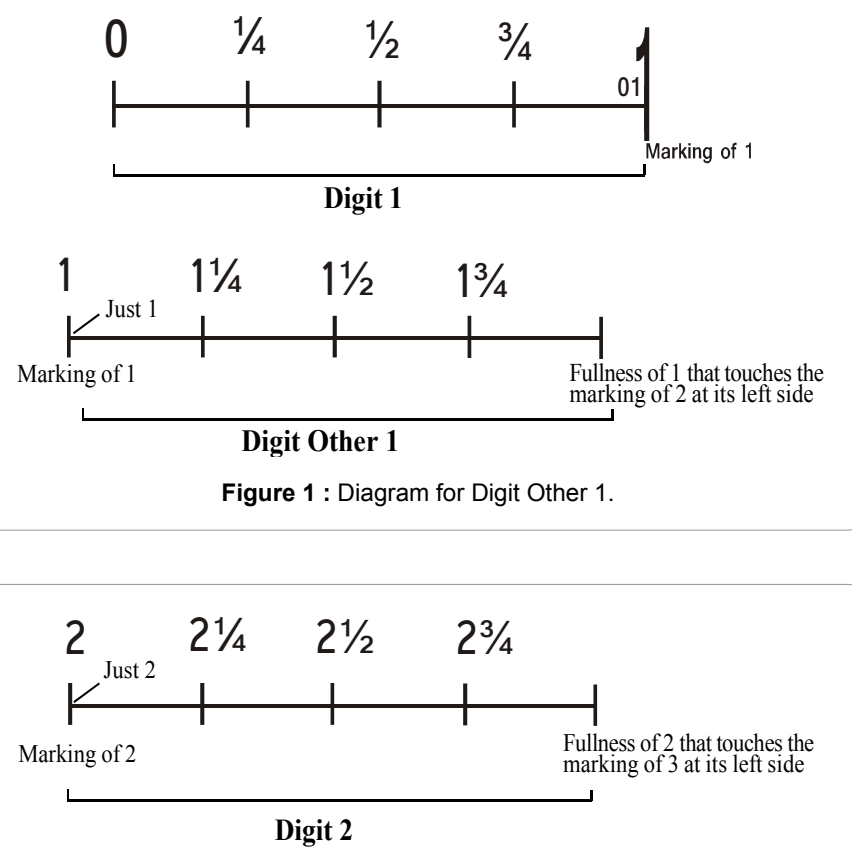

Figure 2: Diagram for Digit 2.

*Corresponding author: Kutty COJ, Department of Mathematics, Promoters of Superscience, Bhagwati Garden, Jain Road, Uttam Nagar, New Delhi, India, Tel: 9899043585; E-mail: superscience_promo@yahoo.in

Received October 23, 2018; Accepted January 02, 2019; Published January 10 2019

Citation: Kutty COJ (2019) The 1 Value Out of the Simple Fractions of 1 Alters the Present 9 Digits. J Appl Computat Math 8: 431.

Copyright: (c) 2019 Kutty COJ. This is an open-access article distributed under the terms of the Creative Commons Attribution License, which permits unrestricted use, distribution, and reproduction in any medium, provided the original author and source are credited. 


\section{From the power of the simple fractions, Digit 1 arises}

The power of the Simple fraction $1 / 4$ is from 0 till the $1 / 4$ point on a measuring scale.

The power of the Simple fraction $1 / 2$ is from 0 till the $1 / 2$ point on a measuring scale.

The power of the Simple fraction $3 / 4$ is from 0 till the $3 / 4$ point on a measuring scale.

The power of 01 is almost the 1 value from 0 till the brimming point of touching the marking of 1 at its left side.

All the Simple fractions of 1 are the Simple fractions of Digit 1 which is the Real 1. Among all these Simple fractions of 1, the 01 alone touches the marking of 1 whereas the power of the totality of all, the Digit 1 arises. So practically 01 is transformed as the Digit 1 (Figure 3).

Again, for measuring any Circle value, 0 at the left side gives double value

For measuring a circle such as the circular clock, the circular planet earth and the circular universe, 0 at the left side is with double value.

This is because every circle starts from 0 and ends in the same 0 point in $360^{\circ}$.

\section{Circle is with exclusive calculation system}

In an encircled fist, there are five gaps between the five fingers. So here the gaps are equal to five fingers' number. Here the numbering of both the fingers and the gaps is the same in Figure 4.

The encircling of the five fingers on the fist is with five gap values, where the numbering of both the fingers and the gap values is the same.

The uniqueness of the circle is again in the starting point and in the ending point. Every circle starts from ' 0 ' and that circle ends in the same ' 0 ' point in $360^{\circ}$. So there is an (once) again ' 0 ' value in every circle with the evaluation of $\frac{0}{0}$.
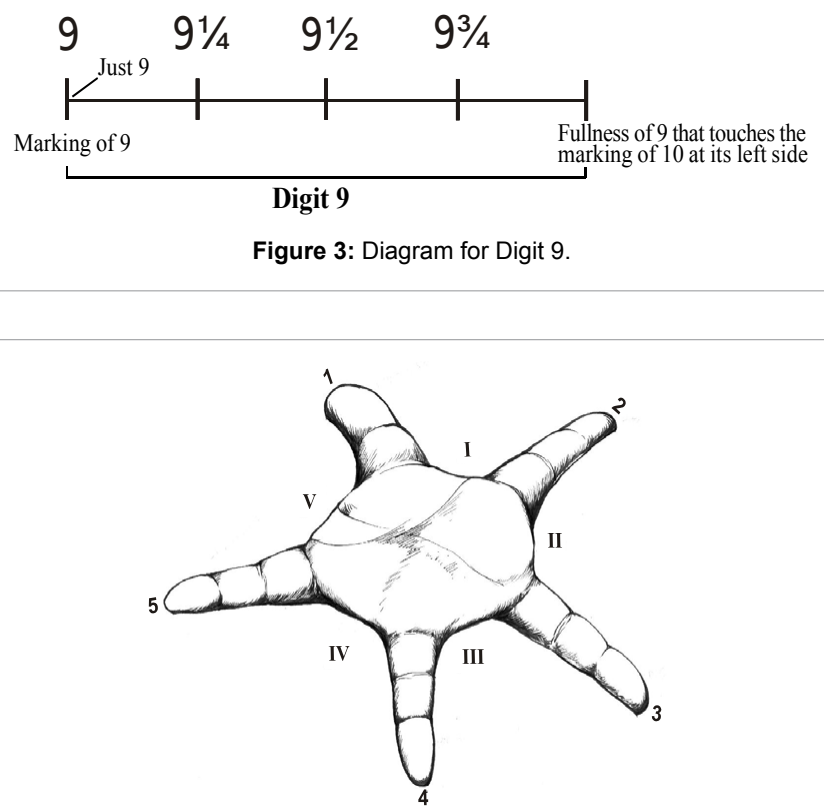

Figure 4: The numbering of both the fingers and the gap values.
The above-said two unique facts are seen exclusively in the circle. So the same theory is seen in the clock, in the circular planet, in the circular stars, and in the circular universe. In the clock, there are two zero values such as the ' 0 ' o'clock as the starting point, and in the same 0 point there is the 12 oclock as the ending point in $360^{\circ}$. Here everyone should know that in reality 12 oclock is the once again counted same ' 0 '. Again on the clock we see and count twelve markings with the same 12 gaps or 12 gap values in between those 12 markings because of the encircled state or being a circle.

Surely the same theory is to be made applicable for all the calculations of the planet circular earth. For every interplanetary journey, surely this unique calculation is necessary and is to be applied for easy and speedy reaching to the other planets, even to the other planets beyond our Solar system.

The Calculation of the space which is with horizontal and vertical lines having ' 0 ' as the starting point

But for the calculation of the space with horizontal and vertical lines, the calculation is starting only from the once counted ' 0 ' being the valuable ' 0 ', which now we see on every scale by its starting from ' 0 ' point on all the scales.

From 0 to 9, there are IX gap values, because 0 is the starting point to scale the space.

\section{Counting value is the very normal value from the paleolithic age}

The counting starts from ' 1 ', where 0 at the left side is valueless. Not only is 0 at the left side valueless in the counting, but the Simple fractions of 1 till 01 at the left side as 1/4, 1/2, 3/4, 01 are also valueless in the counting, because counting starts from the Mixed fractions of 1 at the right side where there are $1 \frac{1}{4}, 1 \frac{1}{2}, 1^{3} \frac{1}{4}$ etc. which is the Other 1 . So in between 1 to 9 there are only 8 gap values (Figure 5).

This counting theory is totally different from the calculation of the circle theory and from the calculation of the space theory. Using the calculation of the counting theory either for the circle or for the space is limiting the calculation with wrong result in the enormous level of calculation.

By this reason, we are not able to calculate or measure the universal phenomena correctly and exactly.

This limitation in calculation is straightway seen through the VIII gap values in between 1 to 9 while the counting starts from 1 .

\section{Simple Fractions of 1 Alter the Totality of Nine Digits to Ten Digits}

The Simple fractions of 1 give a Real 1 value and surely it is the Digit 1. If it is so, there are ten Digits; where from the Other 1 as the Mixed fractions of 1 itself, further there are nine digits besides the Digit 1 (Figure 6)

\section{The Ten Digits One By One}

1. The Simple fractions of 1 from 0 to 01 , that is till the marking of 1 give the one value as the Digit 1 .

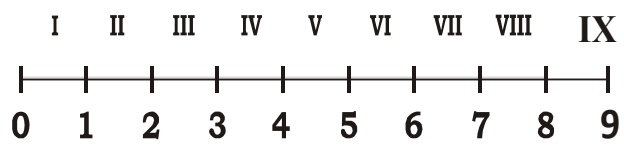

Figure 5: The space with horizontal and vertical lines. 


\section{$\begin{array}{llllllll}\text { I } & \text { II } & \text { III } & \text { IV } & \text { V } & \text { VI } & \text { VII } & \text { VIII }\end{array}$

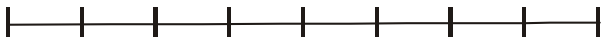 \\ $\begin{array}{lllllllll}1 & 2 & 3 & 4 & 5 & 6 & 7 & 8 & 9\end{array}$}

Figure 6: Calculation is straightway seen through the VIII gap.

From the marking of $0 \rightarrow 1 / 4 \rightarrow 1 / 2 \rightarrow 3 / 4 \rightarrow 01$ that touches the marking of 1 at its left side, there arises the Real 1 as the Digit 1 out of all the Simple fractions of 1 .

2. The Mixed fractions of 1 from the Just 1 to the fullness of 1 give the

\section{Digit Other 1.}

Where there is the marking of 1 there is the Just 1 , further with $1 \frac{1 / 4}{1} \rightarrow 1^{1 / 2} \rightarrow 1^{3 / 4} \rightarrow$ fullness of 1 that denote the Digit Other 1 .

3. The Mixed fractions of 2 from the Just 2 to the fullness of 2 give the Digit 2. Where there is the marking of 2 there is the Just 2, further with $2 \frac{1 / 4}{2} \rightarrow 2^{1 / 2} \rightarrow 2^{3 / 4} \rightarrow$ fullness of 2 that denote the Digit 2.

4. The Mixed fractions of 3 from the Just 3 to the fullness of 3 give the Digit 3. Where there is the marking of 3 there is the Just 3, further with $3 \frac{1 / 4}{1} \rightarrow 3^{1 / 2} \rightarrow 3^{3 / 4} \rightarrow$ fullness of 3 that denote the Digit 3.

5. The Mixed fractions of 4 from the Just 4 to the fullness of 4 give the Digit 4. Where there is the marking of 4 there is the Just 4 , further with $4^{1 / 4} \rightarrow 4^{1 / 2} \rightarrow 4^{3 / 4} \rightarrow$ fullness of 4 that denote the Digit 4.

6. The Mixed fractions of 5 from the Just 5 to the fullness of 5 give the Digit 5. Where there is the marking of 5 there is the Just 5 , further with $5^{1 / 4} \rightarrow 5^{1 / 2} \rightarrow 5^{3 / 4} \rightarrow$ fullness of 5 that denote the Digit 5.

7. The Mixed fractions of 6 from the Just 6 to the fullness of 6 give the Digit 6. Where there is the marking of 6 there is the Just 6 , further with $6^{1 / 4} \rightarrow 6^{1 / 2} \rightarrow 6^{3 / 4} \rightarrow$ fullness of 6 that denote the Digit 6.
8. The Mixed fractions of 7 from the Just 7 to the fullness of 7 give the Digit 7 . Where there is the marking of 7 there is the Just 7 , further with $71 / 4 \rightarrow 7^{1 / 2} \rightarrow 7^{3 / 4} \rightarrow$ fullness of 7 that denote the Digit 7.

9. The Mixed fractions of 8 from the Just 8 to the fullness of 8 give the Digit 8. Where there is the marking of 8 there is the Just 8, further with $8^{1 / 4} \rightarrow 8^{1 / 2} \rightarrow 8^{3} / 4 \rightarrow$ fullness of 8 that denote the Digit 8.

10. The Mixed fractions of 9 from the Just 9 to the fullness of 9 give the Digit 9. Where there is the marking of 9 there is the Just 9, further with $\mathbf{9 1}^{1 / 4} \rightarrow \mathbf{9}^{1 / 2} \rightarrow \mathbf{9}^{3 / 4} \rightarrow$ fullness of 9 that denote the Digit 9.

\section{References}

1. Acharya S, Gurung DB, Saxena VP (2012) Time dependent temperature distribution model in layered human dermal part. Journal of Science Engineering and Technology 8: 66-76.

2. Kingma B, Frijns A, Van Marken Lichtenbelt W (2012) The thermo neutral zone: implications for metabolic studies. Frontiers in Bioscience 4: 1975-1985.

3. Nadel ER, Bullard RW, Stolwijk JA (1979) Importance of skin temperature in the regulation of sweating. J Appl Physiol 31: 430-437.

4. Wyndham $\mathrm{CH}$, Morrison JF, Williams CG (1965) Heat reaction of male and female caucasians. J Appl Physiol 20:357-364.

5. Gurung DB, Saxena VP (2010) Peripheral temperature distribution in human subjects exposed to wind ow. International eJournals of Mathematics and Engineering 73:728-740.

6. Gurung DB, Saxena VP, Adhikary PR (2009) Fem approach to one dimensional unsteady state temperature distribution in the dermal parts with quadratic shape function. J Appl Math Informat 27: 301-313.

7. Gokul KC, Gurung DB, Adhikary PR (2015) Mathematical model: comparative study of thermal effect of laser in corneal refractive surgeries. Application and Applied Mathematics 10: 609-619.

8. Goldman RF (1998) Standards for human exposure to heat, Environmental ergonornics, 1998.

9. Gurung DB (2012) Two dimensional temperature distribution model in human der-mal region exposed at low ambient temperature with air flow, Journal of Science, Engineering and Technology 8:11-24.

10. Guyton C, Hall E (2009) Text book of medical physiology, second edition Elsevier. 